\title{
Potential Therapeutic Effects of Vitamin E and C on Placental Oxidative Stress Induced by Nicotine: An In Vitro Evidence
}

\author{
Chiara Gallo ${ }^{1}$, Paolo Renzi ${ }^{1}$, Stefano Loizzo ${ }^{2}$, Alberto Loizzo $^{2}$, Sonia Piacente ${ }^{3}$, Michela Festa ${ }^{3}$, \\ Mariella Caputo ${ }^{3}$, Mario Felice Tecce ${ }^{3}$ and Anna Capasso*, ${ }^{3}$
}

\author{
${ }^{I}$ Dipartimento di Psicologia, Universita' di Roma "La Sapienza" Via dei Marsi 78, (00185) Roma; ${ }^{2}$ Istituto Superiore di \\ Sanità, viale Regina Elena 299 (00161) Roma; ${ }^{3}$ Dipartimento di Science Farmaceutiche, Università di Salerno, Via \\ Ponte Don Melillo (84084), Fisciano, Salerno, Italy
}

\begin{abstract}
There have been a few studies that examined the oxidative stress effects of nicotine during pregnancy and lactation. The adverse effect of prenatal smoking exposure on human fetal development and growth has been a major public health issue. Active or passive smoking during pregnancy can result in a wide variety of adverse outcomes, including intrauterine growth retardation (IUGR), prematurity, stillbirth, and the sudden infant death syndrome. Smoking in pregnancy has also been associated with an increased risk of attention deficit and learning problems in childhood. Some studies argued that as a principal component of tobacco smoke, nicotine alone is responsible for the majority of negative reproductive outcomes. Nicotine and its major metabolite cotinine can cross the placental barrier. The level of nicotine in fetal tissues was found to be equal to or greater than the plasma nicotine level in the mothers. The oxidative stress induce by nicotine has been increasingly postulated as a major contributor to endothelial dysfunction. A large body of research has investigated the potential role of antioxidant nutrients in the prevention of endothelial dysfunction in women. Therefore, the present study was undertaken to assess the potential benefit of antioxidant supplementation on markers of placental oxidative stress in an in vitro model of endothelial dysfunction induced by nicotine, since it was previously found that nicotine is able to trigger the placental secretion of stress molecules. In this regard, we evaluated the effects of vitamin $\mathrm{C}$, vitamin $\mathrm{E}$ and $\mathrm{N}$-acetylcysteine (NAC), alone or in combination, in placental villi culture after exposure to nicotine. The effect of antioxidant nutrients on trophoblast cells proliferation and vitality was also evaluated. The results obtained suggest that in a patho-physiological condition, such as endothelial dysfunction induced by nicotine, the deleterious effect of reactive oxygen species may be counteracted by an antioxidant therapy, and there is the need to investigate the optimum dosing and timing of antioxidants administration, since an inappropriate antioxidant treatment in pregnant women may have deleterious consequences, reducing placental cells proliferation until to cell death.
\end{abstract}

Keywords: Nicotine, oxidative stress, vitamins.

\section{INTRODUCTION}

Preeclampsia (PE) is a human pregnancy-specific disorder that adversely affects maternal vascular function and fetal intrauterine growth, and is the leading cause of maternal and perinatal mortality in developed countries [1]. A potential role for oxidative stress in the pathophysiology of PE emerged in the last years [2-4]. Synthesis of free radicals by a dysfunctional placenta and endothelium seems to play a central role in this association, since they, through the oxidative damage of biomolecules and lipid peroxidation, contribute to the systemic endothelial cell dysfunction and activation accounting for the clinical expression of the disease $[5,6]$.

On this basis, antioxidants such as vitamin $\mathrm{C}$ and vitamin E have been proposed as potential therapeutic or prophylactic treatment for PE [6]. Accordingly, Chappell et al. [7] in a randomised trial of 283 women at high risk for $\mathrm{PE}$, showed a reduction in the incidence of the disease in

*Address correspondence to this author at the Department of Pharmaceutical Sciences, University of Salerno, Via Ponte Don Melillo (84084), Fisciano, Salerno, Italy; Tel/Fax: +39-089-969744;

E-mail: annacap@unisa.it women treated with vitamin $\mathrm{C}$ and $\mathrm{E}$ from the second trimester of pregnancy [7]. This effect was followed by a diminution of the indices of oxidative stress towards values that were observed in a group of healthy women [8].

Vitamin $\mathrm{C}$ and $\mathrm{E}$ are two essential nutrients that can scavenge free radicals and constitute a strong line of defence in retarding reactive oxygen species (ROS)-induced cellular damage. Indeed, vitamin E, mainly $\alpha$-tocopherol, is the major peroxyl radical scavenger in biological lipid phases, such as membranes. Its antioxidant action has been ascribed to its ability to chemically act as a lipid-based free radical chain-breaking molecule, thereby inhibiting lipid peroxidation [9]. With respect to vitamin $C$, it has been shown to scavenge free radicals directly in the aqueous phases of cells and circulatory system, and also to protect membranes and other hydrophobic compartments from damage by rigenerating the antioxidant form of vitamin $\mathrm{E}$ [10]. A synergistic effect between the two vitamins in vitro and in vivo has been also demonstrated [9]. Indeed, the proposed mechanism of action was that when vitamin $\mathrm{E}$ intercepts a radical thus forming a complex $\alpha$-tocopheroxylradical which can be reduced back to $\alpha$-tocopherol by vitamin $\mathrm{C}$ or other reducing agents, thus attenuating the 
propagation of free radical reactions $[11,12]$. Thus vitamin $\mathrm{C}$ prevents the prooxidant activity of vitamin $\mathrm{E}$ by decreasing the activity of tocopheroxyl radical to $\alpha$ tocopherol, thereby contributing to increased total antioxidant status and reducing oxidative stress [13]. With respect to oxidative stress and PE, previous studies showed that prenatal nicotine exposure resulted in inhibition of fetal growth, also, nicotine in the maternal placenta may be involved with the observed increase in oxidative stress and lipid peroxidation. The above effects of nicotine on the maternal placenta may also contribute to an increased susceptibility of the fetus to environmental toxinsin [14].

Also, the adverse effect of prenatal smoking exposure on human fetal development and growth has been a major public health issue. Active or passive smoking during pregnancy can result in a wide variety of adverse outcomes, including intrauterine growth retardation (IUGR), prematurity, stillbirth, and the sudden infant death syndrome. Smoking in pregnancy has also been associated with an increased risk of attention deficit and learning problems in childhood [1-3]. Some studies argued that as a principal component of tobacco smoke, nicotine alone is responsible for the majority of negative reproductive outcomes. Nicotine and its major metabolite cotinine can cross the placental barrier. The level of nicotine in fetal tissues was found to be equal to or greater than the plasma nicotine level in the mothers [1-3]. The oxidative stress induced by nicotine has been increasingly postulated as a major contributor to endothelial dysfunction [15-20].

There have been a few studies that examined the oxidative stress effects of nicotine during pregnancy and lactation. Therefore, the present study was primarly designed to assess the potential benefit of antioxidant supplementation on markers of placental oxidative stress [malondialdehyde (MDA), and glutathione (GSH)] induced by nicotine, as well as its effect on trophoblast cells proliferation and vitality. In this regard, we evaluated the effects of vitamin $\mathrm{C}$ and $\mathrm{E}$ alone or in combination, but also those of $\mathrm{N}$-acetylcysteine (NAC), the acetylated variant of the amino acid L-cysteine, that is known to stimulate GSH synthesis, to promote detoxification and to act directly as free radical scavenger.

\section{MATERIALS AND METHODS}

\section{Placental Explants Culture}

Placentae were obtained under sterile conditions from normal pregnancies undergoing elective caesarean section at term. Maternal consent was obtained according to the guidelines of Ethics Committee. Chunks of placental cotyledons weighing approximately $30 \mathrm{~g}$ were thoroughly rinsed in calcium- and magnesium-free Hanks' solution (HBSS), villous tissue was identified and isolated from membranes, large vessels, decidua and connective tissue under a dissection microscope. Small clusters of placental villi (50 mg/wet weight) were placed in a 24 -well plastic plates and cultured in Ham's F10 medium supplemented with $10 \% \mathrm{FBS}, 2 \mathrm{mmol} / \mathrm{L}$ L-glutamine, $100 \mathrm{IU} / \mathrm{ml}$ penicillin, and $100 \mu \mathrm{g} / \mathrm{ml}$ streptomycin at $37^{\circ} \mathrm{C}$ under $5 \% \mathrm{CO}_{2}-95 \%$ air. Culture medium was enriched with vitamin $\mathrm{C}$ or vitamin $\mathrm{E}$ or NAC, alone or in combination, at concentration of $5 \mathrm{pM}$. Culture medium was removed after two days of culture and the explants were treated with different concentrations of
Nicotine (0-100 pg/ml), dissolved in fresh Ham's F10 medium, enriched with antioxidants, for $6 \mathrm{~h}$. Indeed, we have shown previously that placental villi exposed to different nicotine concentrations displayed a significant dose-dependent decrease of GSH and a significant dose dependent increase of MDA after $6 \mathrm{~h}$ of treatment (14). Therefore, to investigate whether vitamin $\mathrm{C}$, vitamin $\mathrm{E}$ and NAC blocks the oxidative stress condition triggered by nicotine, we measured their influence on GSH and MDA content in placental villi after $6 \mathrm{~h}$ of ET-1 treatment.

Experiments were performed at least six times, using a single placenta for each one.

\section{Measurement of GSH and LPOs}

For GSH measurement, placental tissues were homogenized using Mixer Mill MM 300 (QIAGEN, Milan, Italy) in EDTA-K $\mathrm{K}^{+}$phosphate buffer $(\mathrm{pH} 7.4)$ and $10 \%(\mathrm{w} / \mathrm{v})$ metaphosphoric acid $(1: 1)$ at $4^{\circ} \mathrm{C}$, centrifuged at $2000 \mathrm{~g}$ for $10 \mathrm{~min}$ and the supernatants were stored at $-80^{\circ} \mathrm{C}$ until the assay. GSH was measured by using a colorimetric assay kit (Cayman-Cayman Chemical Company, USA).

LPOs content was measured by the stable metabolite MDA with a HPLC assay as previously described (21). Placental explants were homogenized in mixture $(1: 1)$ of $0,04 \mathrm{~mol} / \mathrm{L}$ TRIS-HCl buffer $(\mathrm{pH} 7.4)$ and a solution of acetonitrile containing $0,1 \%$ butyl hydroxytoluene $\left(4^{\circ} \mathrm{C}\right)$, to prevent the artificial oxidation of polyunsaturated free fatty acid during the assay, and centrifuged at $3000 \mathrm{~g}$ for $15 \mathrm{~min}$ at $4{ }^{\circ} \mathrm{C}$. Supernatants were stored at $-80^{\circ} \mathrm{C}$ until the assay.

\section{JEG-3 Choriocarcinoma Cells Culture}

JEG-3 cells were obtained from the American Type Culture Collection (ATCC, Rockville, MD; passage number 125), and were used within seven passages. JEG-3 cells were maintained routinely in RPMI medium supplemented with $10 \% \mathrm{FBS}, 2 \mathrm{mmol} / \mathrm{L}$ L-glutamine, $100 \mathrm{IU} / \mathrm{ml}$ penicillin, and $100 \mu \mathrm{g} / \mathrm{ml}$ streptomycin at $37^{\circ} \mathrm{C}$ under $5 \% \mathrm{CO}_{2}-95 \%$ air.

\section{Effect of Antioxidants on JEG-3 Cells Proliferation After ET-1 Treatment}

JEG-3 cells were plated at a density of $5 \times 10^{3}$ cells/well in 96-well plastic plates and were allowed to adhere to the wells overnight, then the cells were treated with different concentrations of the nicotine $(0-100 \mathrm{pg} / \mathrm{ml})$ in RPMI medium enriched with vitamin $\mathrm{C}$, vitamin $\mathrm{E}$ and $\mathrm{NAC}$ alone or in combination. After $24 \mathrm{~h}, \mathrm{JEG}-3$ vitality and proliferation rate were determined with (3-[4,5dimethylthiazol-2-yl]-2,5-diphenyltetrazolium bromides (MTT) assay. MTT stock solution $(5 \mathrm{mg} / \mathrm{ml})$ was added to each well being assayed to equal one tenth the original culture volume and incubated for $4 \mathrm{~h}$. At the end of the incubation period converted dye was solubilized with acidic isopropanol $(0,04-0,1 \mathrm{~N} \mathrm{HCl}$ in absolute isopropanol). Absorbance of converted dye was measured at a wavelength of $570 \mathrm{~nm}$ with background subtraction at $630 \mathrm{~nm}$.

\section{Antiproliferative Activity of Vitamin C and E and NAC on JEG-3 Cells}

JEG-3 cells were plated at a density of $5 \times 10^{3}$ cells/well in 96-well plastic plates and were allowed to adhere to the wells overnight, then the cells were treated with different 


\section{A}

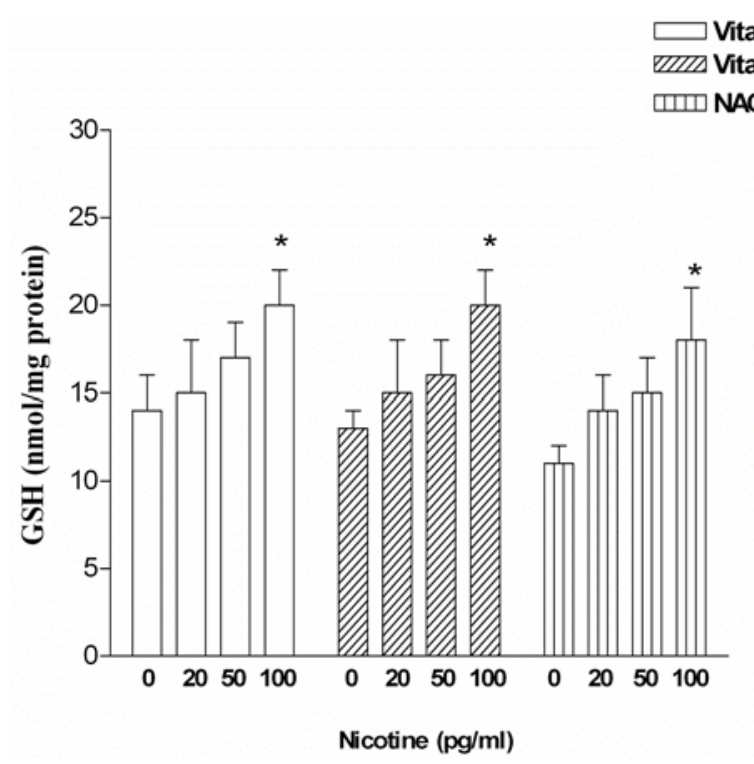

B $\square$ Vitamin C+Vitamin E CD NAC+Vitamin E

Fig. (1). Influence of vitamin C, vitamin E and NAC, alone (A) or in combination (B), on GSH levels in placental villi exposed for 6 h to different concentration of nicotine $(* \mathrm{P}<0.05 ; * * \mathrm{P}<0.01)$.

concentrations $\left(5 \times 10^{-12}-5 \times 10^{-8} \mathrm{M}\right)$ of vitamin $\mathrm{C}$, vitamin $\mathrm{E}$ and NAC for $24 \mathrm{~h}$. JEG-3 proliferation were determined by MTT assay, like described above.

\section{Statistical Analysis}

Explants data were expressed as nmol/mg prot for GSH, and as nmol/gr tissue for MDA. JEG-3 data were expressed as per cent variations respect to control (each point represents six experiments, performed in triplicate) to better evidence the differences between the various treatments with nicotine. The ANOVA for repeated measures test followed by Bonferroni post-hoc test was applied for statistical comparison. Differences were considered significant at a value of $\mathrm{P}<0.05$.

\section{RESULTS AND DISCUSSION}

GSH levels in explants exposed to nicotine (20-100 $\mathrm{pg} / \mathrm{ml}$ ) in presence of vitamin C $5 \mathrm{pM}$ did not differ from those in control explants (Fig. 1A). Similar results were observed in presence of NAC $5 \mathrm{pM}$, except for nicotine 100 $\mathrm{pg} / \mathrm{ml}$ where it can possible to note a significant $(\mathrm{P}<0.05)$ increase of GSH levels respect to control (Fig. 1A). However, when placental villi were treated with nicotine in presence of vitamin E $5 \mathrm{pM}$, we observed a significant $(\mathrm{P}<0.0001)$ increase of GSH content that showed a dosedependence respect to nicotine concentration (Fig. 1A). We also tested the effect of a combination of vitamin $\mathrm{C}$ and $\mathrm{E}$, and NAC and vitamin E, and we found no change in GSH levels in the first case, but a significant $(\mathrm{P}<0.001)$ increase of GSH content depending on nicotine concentration in the second case (Fig. 1B).

Table 1 shows the \% variation of MDA induced by nicotine $(20-100 \mathrm{pg} / \mathrm{ml})$ in the placental villi. Nicotine, after $6 \mathrm{~h}$, induced a significant increase of MDA in the placental villi. However, when placental explants were treated with nicotine in presence of vitamin $\mathrm{C}$, vitamin $\mathrm{E}$ and NAC (5 pM), MDA levels were totally blocked (Table 1).

Table1. The Effect of Nicotine Alone (20-100 pg/ml) and in Presence of Vitamin C, Vitamin E and NAC (5pM) on MDA Level in the Placental Villi

\begin{tabular}{|c|c|c|c|c|}
\hline $\begin{array}{c}\text { Nicotine Administration } \\
(\mathbf{6 h})\end{array}$ & $\begin{array}{c}\text { MDA Levels Nicotine } \\
\text { Alone } \\
(\boldsymbol{\%} \text { of control) }\end{array}$ & $\begin{array}{c}\text { MDA Levels } \\
\text { Nicotine+Vitamin C } \\
(\boldsymbol{\%} \text { of control) }\end{array}$ & $\begin{array}{c}\text { MDA Levels } \\
\text { Nicotine+Vitamin E } \\
(\boldsymbol{\%} \text { of control) }\end{array}$ & $\begin{array}{c}\text { MDA Levels } \\
\text { Nicotine+NAC } \\
(\% \text { of control) }\end{array}$ \\
\hline \hline $\begin{array}{c}\text { Control } \\
\text { Nicotine } 0 \mathrm{pg} / \mathrm{ml}\end{array}$ & 100 & 100 & 100 & 100 \\
\hline $\begin{array}{c}\text { Nicotine } \\
20 \mathrm{pg} / \mathrm{ml}\end{array}$ & $113 \pm 31$ & $114 \pm 21$ & $105 \pm 10$ & $101 \pm 11$ \\
\hline $\begin{array}{c}\mathrm{Nicotine} \\
50 \mathrm{pg} / \mathrm{ml}\end{array}$ & $130 \pm 12^{*}$ & $103 \pm 12^{\S \S}$ & $11^{\S \S}$ & $102 \pm 10^{\S \S}$ \\
\hline $\begin{array}{c}\mathrm{Nicotine} \\
100 \mathrm{pg} / \mathrm{ml}\end{array}$ & $207 \pm 26^{* *}$ & $110 \pm 21^{\S \S}$ & $107 \pm 10^{\S \S}$ & $101 \pm 11^{\S \S}$ \\
\hline
\end{tabular}

Results are expressed as mean+S.E.M.. ${ }^{*} \mathrm{P}<0.05$ : $* * \mathrm{P}<00.1$ was accepted as indicative of significant difference between groups $\left(\right.$ nicotine $\mathrm{vs}$ control, $\mathrm{n}=5$ ). ${ }^{\S \S} \mathrm{P}<00.1$ (nicotine+vitamins vs nicotine alone). 
A

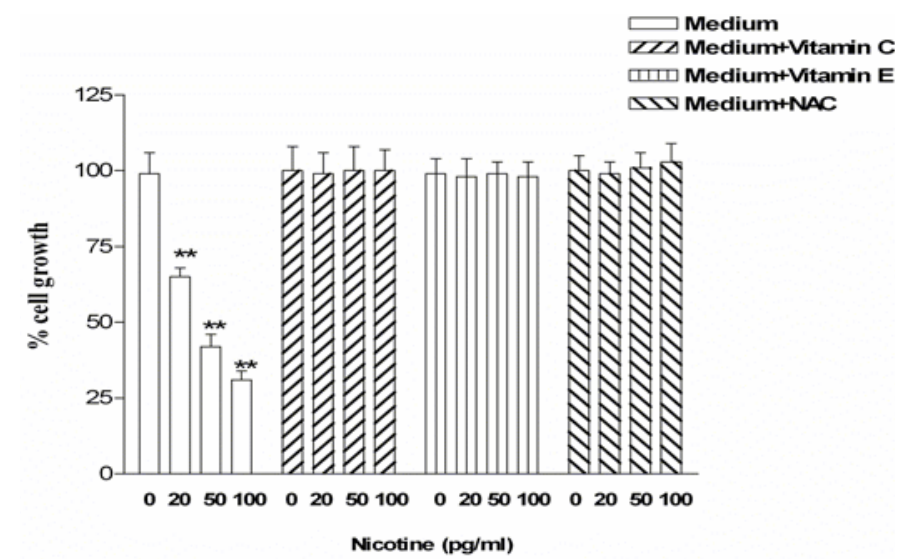

B

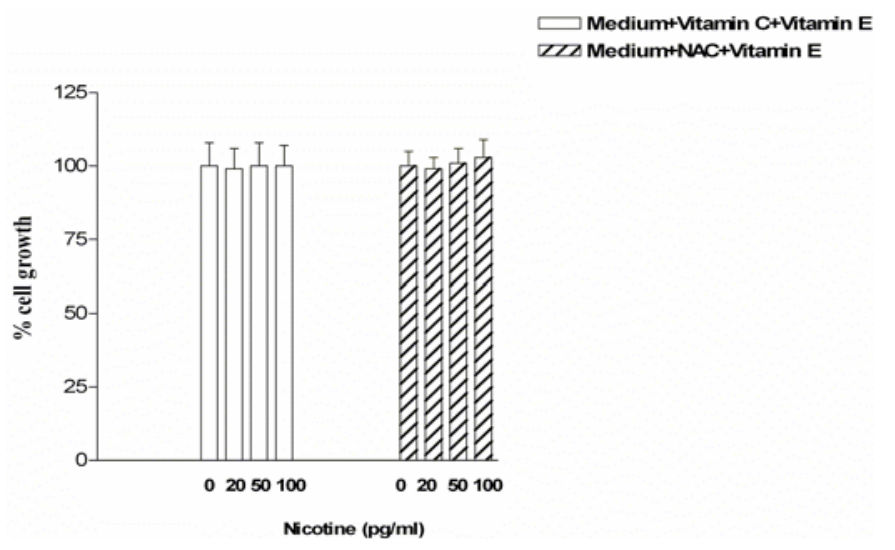

Fig. (2). Proliferation in JEG-3 cells. Placental cells were exposed to nicotine in absence of antioxidant nutrient and in presence of vitamin C, vitamin $\mathrm{E}$ and NAC, alone (A) or in combination $(\mathbf{B})$. Cell growh was estimated after $24 \mathrm{~h}$ by MTT method. Results are expressed as mean \pm $\mathrm{SD}$ of six experiments, each one performed in triplicate. $* * \mathrm{P}<0.01$.

The experiments performed to evaluate the influence of the vitamin $\mathrm{C}$, vitamin $\mathrm{E}$ and NAC on cell vitality and proliferation after $24 \mathrm{~h}$ of nicotine treatment showed that nicotine significantly $(\mathrm{P}<0 \cdot 001)$ and dose-dependently decreased the proliferation rate of the JEG-3 cells (Fig. 2A). On the contrary, vitamin $\mathrm{C}$, vitamin $\mathrm{E}$ and NAC blocked totally the inhibitory effect of nicotine (Fig. 2A).

Finally, the combination of two antioxidants (vitamin C plus vitamin $\mathrm{E}$ or NAC plus vitamin $\mathrm{E}$ ) were used in combination also blocked the inhibitory effect of nicotine on cells proliferation (Fig. 2B).

We also tested the effect of the increasing concentrations $\left(5 \times 10^{-12}-5 \times 10^{-8} \mathrm{M}\right)$ of vitamin $\mathrm{C}$, vitamin $\mathrm{E}$ and NAC on JEG-3 cells proliferation. Vitamin $\mathrm{C}$ showed a marked antiproliferative effect, achieving an inhibition of cell growth until to $70 \%$ at higher doses. The effect of the NAC and the vitamin $\mathrm{E}$ was more moderate respect to the vitamin $\mathrm{C}$ and the maximum inhibition was of the $27 \%$ (Fig. 3).

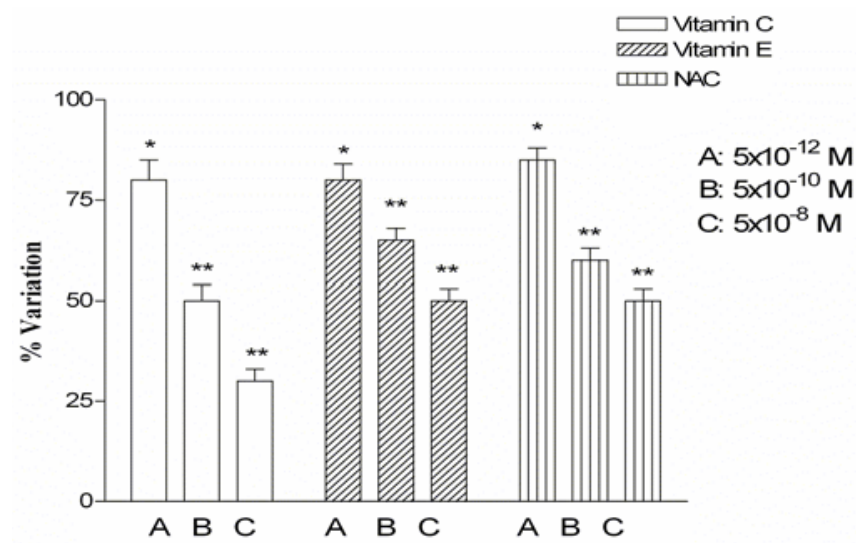

Fig. (3). Antiproliferative effect in JEG-3 cells exposed to increasing concentrations of vitamin C, vitamin E and NAC. Cell proliferation was estimated after $24 \mathrm{~h}$ by MTT method. Results are expressed as mean $\pm \mathrm{SD}$ of six experiments, each one performed in triplicate. $* \mathrm{P}<0.05 ; * * \mathrm{P}<0.01$.

The present study was designed to value the hypothesis that well known antioxidants, such as vitamin $\mathrm{C}$, vitamin $\mathrm{E}$ and NAC, may lead to an improvement in the oxidative stress, since endothelial and placental dysfunction from oxidative stress [5-6]. As consequence, antioxidants have been proposed as a potentially advantageous prophylactic measure for endothelial and placental dysfunction [2-4], since treatment with vitamin $\mathrm{E}$ and $\mathrm{C}$ have been reported to reduce the incidence of endothelial and placental dysfunction in women and to decrease the biochemical indices of oxidative stress [8]. Moreover, in patients with severe endothelial and placental dysfunction plasma $\alpha$-tocopherol was significantly decreased compare with controls, which is thought to be caused by the fact that antioxidants may be utilized to a greater extent to counteract free radicalmediated cell disturbances, resulting in a reduction in their plasma levels [11, 12].

In the present study we used an in vitro model to assess the effect vitamin C, vitamin E and NAC on oxidative stress by nicotine, since previous studies showed that prenatal nicotine exposure resulted in inhibition of fetal growth, also, nicotine in the maternal placenta may be involved with the observed increase in oxidative stress and lipid peroxidation thus increasing susceptibility of the fetus to environmental toxins [14-20].

Briefly, we found that supplementation with vitamin C, vitamin $\mathrm{E}$ and $\mathrm{NAC}$, alone or in combination, prevented the nicotine-1-induced decrease of GSH, an antioxidant molecule that protects cells from reactive oxygen species [21], as well as the nicotine-induced secretion of MDA, an oxidative stress molecole that plays a central role in oxidative damage, since it has toxic effect on cells by disorganizing oxidative phosphorilation in mitochondria and by reacting with proteins and DNA bars [22-27].

Vitamin $\mathrm{C}$ is a potent scavenger of superoxide radicals and may thus have helped to maintain intracellular GSH concentration, in fact no changes were observed in total content of tripeptide GSH in placental villi exposed to nicotine in presence of vitamin C. On the contrary, we observed an increasing of GSH content when placental villi were exposed to nicotine in presence of vitamin E and NAC. We can explain this as an adaptive response to elevated levels of oxidizing species that elicit a specific compensatory 
increase in antioxidant molecule activities. Vitamin E, in fact, is the major peroxyl radical scavenger in biological lipid phases such as membranes. Its antioxidant action has been ascribed to its ability to chemically act as a lipid-based free radical chain-breaking molecule, thereby inhibiting lipid peroxidation and protecting the organism against oxidative damage. Indeed, the interaction between vitamins $\mathrm{C}$ and $\mathrm{E}$ in the antioxidant defense of biochemical systems is well established because vitamin $\mathrm{C}$ can reduce tocopheroxyl radicals directly or indirectly and thus support the antioxidant activity of vitamin E. Upon oxidation these micronutrients need to be regenerated in the biological setting, hence the need for further coupling to nonradical reducing systems such as GSH. Because the metabolism of the reactive species should be regulated selectively at or near the sites of their generation, increases in the expression of these reducing systems in preeclamptic placentas would act as a protective mechanism by which placental cells minimize tissutal oxidative damage. Same conclusions we can hypothesize for NAC, used both as a precursor in the synthesis of GSH and as a direct radical scavenger. Indeed, our results shows an inhibition of the MDA production, one of the most markers of secondary end products of lipid peroxidation, supporting the evidence of the protective effect of vitamin supplementation in placental villi exposed to nicotine since the process of lipid peroxidation of membranes has been implicated as one of the primary events in oxidative cellular damage and has been shown to be associated with fine structure disturbance and subsequent function loss of biological membranes. The second important result of this study is the opposite effect of the antioxidant substances on basic cell physiological process. Indeed, vitamin $C$, vitamin $E$ and NAC improved cell survival when JEG-3 cells were exposed to nicotine, but increasing concentrations of these nutrients were able to induce cell death and to block cell proliferation when JEG-3 were maintained in culture without nicotine.

\section{CONCLUSIONS}

In conclusion, vitamin $\mathrm{C}$, vitamin $\mathrm{E}$ and $\mathrm{NAC}$, alone or in combination, protect the human placenta against the deleterious effects of reactive oxygen species induced by nicotine, and further support the linkage between nicotine and reactive oxygen species, and a likely explanation of their effect is through this mechanism. These data would support the hypothesis that nicotine would induce an initial free radicals overgeneration, promptly scavenged by supplementation with vitamin $\mathrm{C}$ and $\mathrm{E}$, therefore reinforcing placental resistance to oxidative injury.

\section{REFERENCES}

[1] Roberts, J.M.; Hubel, C.A. Is oxidative stress the link in the twostage model of pre-eclampsia? Lancet, 1999, 354, 788-789.

[2] Agarwal, A.; Gupta, S.; Sharma. R. Role of oxidative stress in female reproduction. Reprod. Biol. Endocrinol., 2005, 3, 1-21.

[3] Redman, C.W.; Sargent, I.L. Placental debris, oxidative stress and pre-eclampsia Placenta, 2000, 21, 597-602.

[4] Roberts, J.M.; Cooper, D.W. Pathogenesis and genetics of preeclampsia. Lancet, 2001, 357, 53-56.

[5] Redman, C.W.; Sargent. I.L. Latest Advances in Understanding Preeclampsia. Science, 2005, 308, 1592-1594.

[6] Raijmakers, M.T.; van Tits, B.J.; Hak-Lemmers, H.L.; Roes, E.M.; Steegers, E.A.; Peters. W.H. Low plasma levels of oxidized low density lipoprotein in preeclampsia. Acta Obstet. Gynecol. Scand., 2004, 83, 1173-77.

[7] Chappell, L.C.; Seed, P.T.; Briley, A.L.; Kelly, F.J.; Lee, R.; Hunt, B.J.; Parmar, K.; Bewley, S.J.; Shennan, A.H.; Steer, P.J.; Poston, L. Effect of antioxidants on the occurrence of pre-eclampsia in women at increased risk: a randomised trial. Lancet, 1999, 354, 810-816.

[8] Chappell, L.C.; Seed, P.T., Kelly, F.J.; Briley, A.; Hunt, B.J.; Charnock-Jones, D.S.; Mallet, A.; Poston, L. Vitamin E and C supplementation in women at risk of pre-eclampsia is associated with changes in indices of oxidative stress and placental function. Am. J. Obstet. Gynecol., 2002, 187, 777-784.

[9] Salonen, J.T.; Nyyssonen, K.; Salonen, R.; Lakka, H.M.; Kaikkonen, J.; Porkkala-Sarataho, E.; Voutilainen, S.; Lakka, T.A.; Rissanen, T.; Leskinen, L.; Tuomainen, T.P.; Valkonen, V.P.; Ristonmaa, U.; Poulsen, H.E. Antioxidant Supplementation in Atherosclerosis Prevention (ASAP) study: a randomized trial of the effect of vitamins $\mathrm{E}$ and $\mathrm{C}$ on 3-year progression of carotid atherosclerosis. J. Intern. Med., 2000, 248, 377-86.

[10] Chan, A.C. Partners in defense, vitamin E and vitamin C. Can. J. Physiol. Pharmacol., 1993, 71, 725-731.

[11] Zhang, P.; Omaye, S.T. DNA strand breakage and oxygen tension: effects of $\beta$-carotene, $\alpha$-tocopherol and ascorbic acid. Food Chem. Toxicol., 2001, 39, 239-46.

[12] Zhang, P.; Omaye, S.T. Antioxidant and prooxidant roles for $\beta$ carotene, $\alpha$-tocopherol and ascorbic acid in human lung cells Toxicol. In Vitro, 2001, 15, 13-24.

[13] Chen, X.; Touyz, R.M.; Park, J.B.; Schiffrin, E.L. Antioxidant effects of vitamins $\mathrm{C}$ and $\mathrm{E}$ are associated with altered activation of vascular nadph oxidase and superoxide dismutase in stroke-prone SHR. Hypertension, 2001, 38, 606-611.

[14] Wang, Y.; Chen, M.; Yan Y.E.; Xiao F.; Pan, X-L.; Wang, H. Growth retardation of fetal rats exposed to nicotine in utero: possible involvement of CYP1A1, CYP2E1, and P-glycoprotein. Environ. Toxicol., 2008, 24, 33-42.

[15] Coleman, T.; Antoniak, M.; Britton, J.; Thornton, J.; Lewis, S.; Watts, K. Recruiting pregnant smokers for a placebo-randomised controlled trial of nicotine replacement therapy. BMC Health Serv. Res., 2004, 4, 29.

[16] Davies, D.P.; Abernethy, M. Cigarette smoking in pregnancy: Associations with maternal weight gain and fetal growth. Lancet, 1976, 1, 385-387.

[17] Dempsey, D.A.; Benowitz, N.L. 2001. Risks and benefits of nicotine to aid smoking cessation in pregnancy. Drug Saf., 2001, 24, 277-322.

[18] Elsayed, N.M. Antioxidant mobilization in response to oxidative stress: A dynamic environmental-nutritional interaction. Nutrition, 2001, 17, 828-834.

[19] Ernst, M.; Moolchan, E.T.; Robinson, M.L. Behavioral and neural consequences of prenatal exposure to nicotine. J. Am. Acad. Child Adolesc. Psychiatry, 2001, 40, 630-641.

[20] Vaglenova, J.; Birru, S.; Pandiella, N.M.; Breese, C.R. An assessment of the long-term developmental and behavioural teratogenicity of prenatal nicotine exposure. Behav. Brain Res., 2004, 150, 159-170.

[21] Sies, H. Glutathione and its role in cellular functions Free Radic. Biol. Med., 1999, 27, 916-921.

[22] Hubel, C.A.; Roberts, J.M.; Taylor, R.N.; Musci, T.J.; Rogers, G.M.; McLaughlin, M.K. Lipid peroxidation in pregnancy: new perspectives on preeclampsia. Am. J. Obstet. Gynecol., 1989, 161, 1025-1034.

[23] Hubel, C.A.; Griggs, K.C.; McLaughlin, M.K. Lipid perox- idation and altered vascular function in vitamin E deficient rats. Am. J. Physiol. 1989, 256, 1539-1545.

[24] Yanagisawa, M.; Kurihara, H.; Kimura, S.; Tomobe, Y.; Kobayashi, M.; Mitsui, Y.; Yazaki, Y.; Goto, K.; Masaki, T. A novel potent vasoconstrictor peptide produced by vascular endothelial cells. Nature, 1988, 332, 411-415. 
[25] Yanagisawa, M.; Kurihara, H.; Kimura, S.; Goto, K.; Masaki, T. A novel peptide vasoconstrictor, endothelin, is produced by vascular endothelium and modulates smooth muscle $\mathrm{Ca} 2+$ channels. $J$. Hypertens. Suppl., 1988, 6, S188-S191.

[26] Mayne, S.T. Antioxidant nutrients and chronic disease: use of biomarkers of exposure and oxidative stress status in epidemiologic research. J. Nutr., 2003, 3, 933-940.
Shara, M.A.; Dickson, P.H.; Bagchi, D.; Stohs, S.J. Excretion of formaldehyde, malondialdehyde, acetaldehyde and acetone in the urine of rats in response to 2,3,7,8-tetrachlorodibenzo- $p$-dioxin, paraquat, endrin and carbon tetrachloride. J. Chromatogr., 1992, 576, 221-233.

Received: March 30, 2010

Revised: April 30, 2010

Accepted: May 03, 2010

(C) Gallo et al.; Licensee Bentham Open.

This is an open access article licensed under the terms of the Creative Commons Attribution Non-Commercial License (http://creativecommons.org/licenses/by-nc/3.0/) which permits unrestricted, non-commercial use, distribution and reproduction in any medium, provided the work is properly cited. 